\title{
Synthesis of Four SIRT1 Activators Based on an Imidazo[1,2-b]thiazole Structure, in vitro Derived Metabolites and Deuterated Analogs
}

\author{
Sebastian Höppner ${ }^{\mathrm{a}}$, Nils Schlörer ${ }^{\mathrm{b}}$, Wilhelm Schänzer ${ }^{\mathrm{a}}$ and Mario Thevis ${ }^{\mathrm{a}}{ }^{\text {** }}$ \\ ${ }^{a}$ Center for Preventive Doping Research/Institute of Biochemistry, German Sport University Cologne, Germany \\ ${ }^{b}$ Department of Chemistry, Institute of Organic Chemistry, University of Cologne, Germany
}

\begin{abstract}
The enzyme sirtuin 1 (SIRT1) is a major target for the treatment of various metabolic disorders. Herein, a practical synthesis of imidazo[1,2-b]thiazole derivatives, one of the most comprehensively studied class of synthetic SIRT1 activators, is presented. The synthesized SIRT1 activators, the in vitro-identified metabolite of SRT1720, and the eightfold deuterated analytical standards were obtained through a six-step protocol yielding model compounds with a conserved core structure and two variable moieties. A multiplicity of potential SIRT1 activators and metabolites can be prepared with substituents enabling the modification of biological effects.
\end{abstract}

Keywords: Isotope labeling, metabolite, SIRT1 activator, SRT1720, SRT2104.

The enzyme sirtuin 1 (SIRT1) is an important metabolic key regulator and therefore a promising target for the treatment of metabolic disorders such as type II diabetes mellitus $[1,2]$. Since the naturally occurring polyphenol resveratrol was discovered as a SIRT1 activator in 2003 [3] several new artificial SIRT1 activators were developed based on a common template exhibiting different substituents, some of which are exemplified in Fig. (1) [4].

In this context, SIRT1 activators based on an imidazo[1,2-b]thiazole nucleus represent the best studied class of SIRT1 activators including SRT1720, SRT1460 and SRT2104, which were tested in several in vitro and in vivo studies within the last seven years [5-7]. Even though the activation of the enzyme SIRT1 by these low molecular mass compounds was controversially discussed [8-12], a variety of SIRT1 activators is at present undergoing preclinical and clinical studies (SRT2104 [13, 14], SRT2379 [15, 16] and SRT3025) concerning their utility in the treatment of metabolic, inflammatory and cardiovascular diseases. In addition to SIRT1 activators, the synthesis of metabolites and deuterated analogs of known activators (e.g. SRT1720) for mass spectrometric characterization and quantification is of great interest $[17,18]$. Therefore an alternative, efficient and simple route to synthesize SIRT1 activators (Fig. 2) based on an imidazo [1,2-b] thiazole structure (related to SRT1720 and SRT2104) (Fig. 1) is presented. Four SIRT1 activators and an in vitro observed hydroxy metabolite of

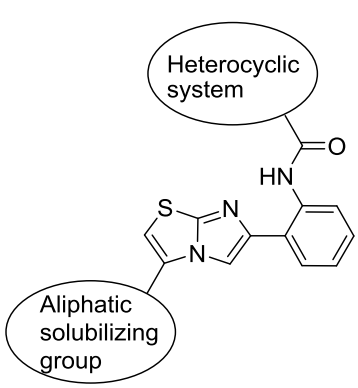

SRT template

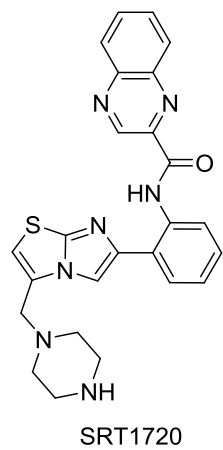

Fig. (1). Selected SIRT1 activators known from literature.

\footnotetext{
*Address correspondence to this author at the Center for Preventive Doping Research/Institute of Biochemistry, German Sport University Cologne, Germany; Tel: +49 2214982 7070; Fax: +49 2214982 7071;
}

E-mail: thevis@dshs-koeln.de

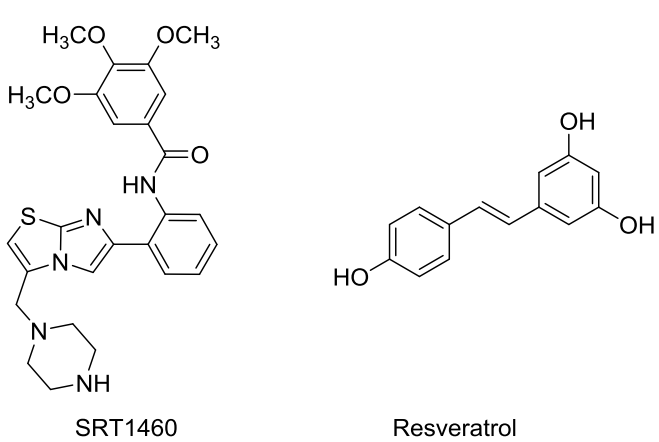

SRT1720 (1b, 2a, 3a, 4a, 5a; Fig. 2) as well as the eightfold deuterated standards $(\mathbf{6 a})$, were synthesized by the procedure described in the following [19].

The alternative synthesis employed a six-step reaction protocol utilizing intermediates $(\mathbf{7}, \mathbf{9}, \mathbf{1 0 a}-\mathbf{b}$, Scheme 1) 


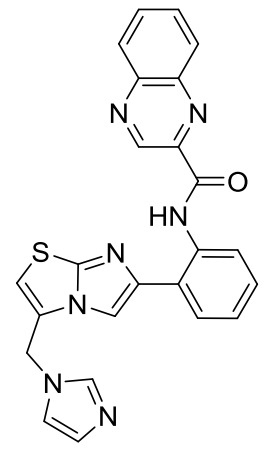

1b

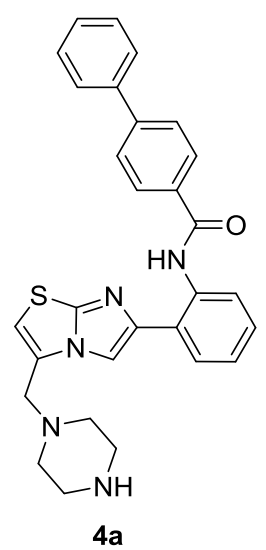

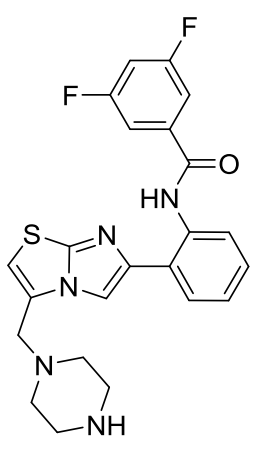

$2 \mathbf{a}$

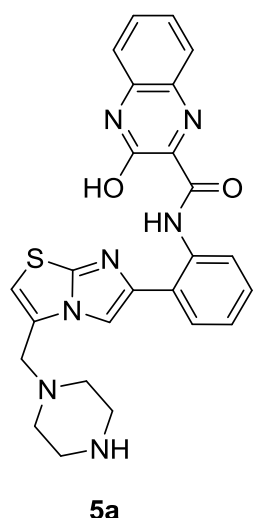

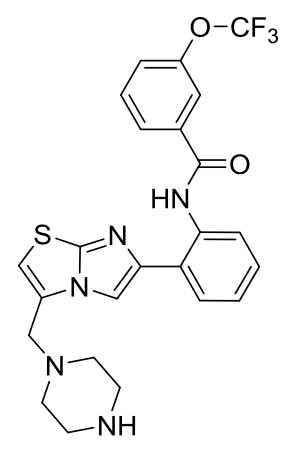

3a

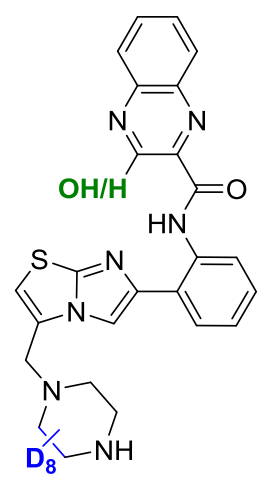

$6 a$

Fig. (2). Synthesized SIRT1 activator (1b-4a), SRT1720 in vitro hydroxy metabolite (5a) and eightfold deuterated analytical standards (SRT1720/in vitro SRT1720 metabolite) (6a).

similar to earlier reports $[2,20,21]$. New aspects particularly concern the reaction steps 2,5 and 6 and the optimization of reaction parameters at various occasions resulting in improved yields as well as an accelerated and more facile synthesis. Four model activators were prepared, differing at two sites $\left(R_{1}\right.$ and $\left.R_{2}\right)$ with the substituent $R_{1}$ being a piperazine (2a-4a), eightfold deuterated piperazine (6a), or imidazole (1b) moiety, and the substituent $R_{2}$ a quinoxaline (1b), 3,5-difluorophenyl (2a), trifluoromethoxyphenyl (3a), biphenyl (4a), or a 3-hydroxy quinoxaline (5a and 6a) residue (Scheme 1). The first three reaction steps, which were identical for all four model activators, were dedicated to the preparation of the imidazo[1,2-b]thiazole core structure (9), which was subsequently extended by consecutively attaching the first (step 4, 10a-b) and the second substituent ( $\operatorname{step}$ six, 1b, 2a, 3a, 4a).

The commercially available ethyl-2-amino-4-thiazolcarboxylate (5) was condensed with bromo-2'-nitro acetophenone (6) under reflux in ethanol. In the literature, several examples for this condensation reaction are given, differing in solvent, reaction time, and purification approach with a wide range in yield (20-86\%) depending on the choice of reactants [21-25]. For the purpose of this study, ethanol and a reflux time of $22 \mathrm{~h}$ resulted in superior yield and purity of the product after crystallization compared to e.g. butanone or acetone (Table 1).

The obtained ester (7) was reduced with DIBAL-H (diisobutyl-aluminium hydride, 1.0 M in methylene chloride,
DCM). Compared to earlier procedures necessitating a twostep reaction [2, 21] including the preparation of the respective carboxylic acid of 7 followed by activation with isobutyl chloroformate for the subsequent reduction with $\mathrm{NaBH}_{4}$, [20, 25] the use of DIBAL-H allowed the considerably faster $(90 \mathrm{~min})$ one-step procedure affording the desired alcohol (8) with yields $(68 \%)$ comparable to the earlier approaches. The mixture was cooled to $-78^{\circ} \mathrm{C}$ and DIBAL-H in DCM (1.0 M) was added within 30 minutes under argon atmosphere. After purification, the alcohol (8) was activated by thionyl chloride for inserting the substituent $\mathrm{R}_{1}$. Here, similar to established procedures, the alcohol (8) was dissolved in DCM and thionyl chloride was added slowly over 30 minutes. After filtration, the desired chloride (9) was obtained without further purification (yield: 99\%). Introducing the substituent $\mathrm{R}_{1}$ (boc-piperazine/ eightfold deuterated boc-piperazine (10a) or imidazole (10b)) was accomplished by dissolving the chloride (9) with the

Table 1. Comparison of employed solvents in reaction step one with regard to reaction time, reaction temperature and yield.

\begin{tabular}{|c|c|c|c|}
\hline Solvent & $\mathbf{t} /[\mathbf{h}]$ & Temp. & Yield/[\%] \\
\hline \hline Butanone & 48 & reflux & 10 \\
\hline Acetone & 20 & reflux & 28 \\
\hline Ethanol & 22 & reflux & 44 \\
\hline
\end{tabular}




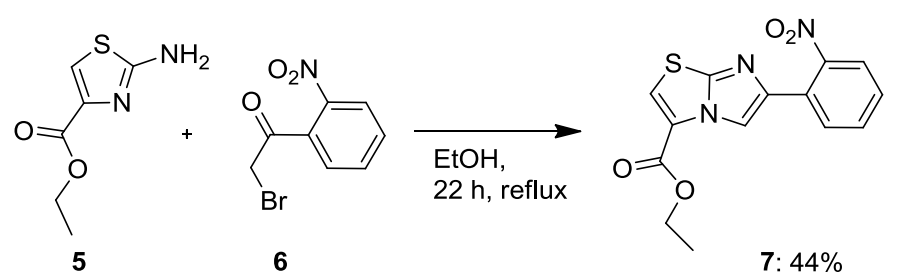
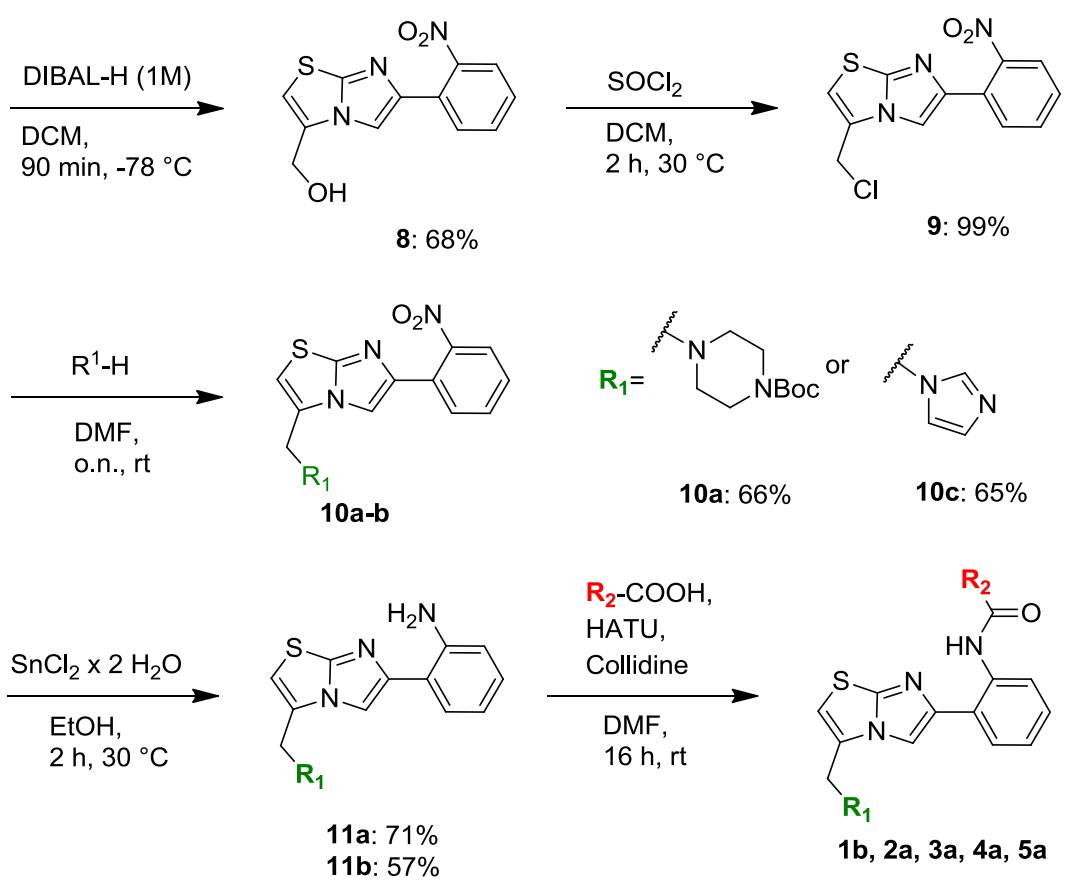

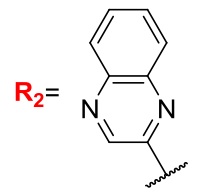

1b: $72 \%$

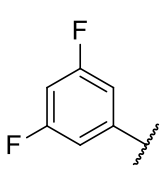

2a: $53 \%$<smiles>CCc1cccc(OC(F)(F)F)c1</smiles>

3a: $81 \%$

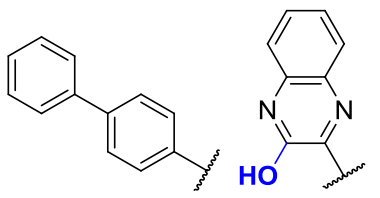

4a: $70 \%$

5a: $75 \%$

Scheme 1. Six-step synthesis of four SIRT1 activators and the SRT1720 in vitro hydroxy metabolite.

corresponding amine in DMF. The reaction mixture was stirred overnight to obtain the coupling products bocpiperazine (10a), yield: 66\%, and imidazole $(\mathbf{1 0 b})$, yield: $65 \%$. The reduction of the nitro function enabling the subsequent insertion of the second substituent $R_{2}$ was achieved by means of $\mathrm{SnCl}_{2}$. This option proved more efficient than sodium hydrosulfide hydrate [21] (reaction time: $24 \mathrm{~h}$ ) or catalytic hydration with $10 \% \mathrm{Pd} / \mathrm{C}$ [2] (reaction time: $60 \mathrm{~h}$ ) as comparable yields were obtained within a considerably shorter reaction (reaction time: 30 min). Educts were dissolved in ethanol and sodium acetate (to buffer the $\mathrm{pH}$ of the reaction mixture and thus exclude any boc-deprotection), $\mathrm{SnCl}_{2}$, potassium carbonate, and sodium iodide were added. The mixture was stirred at $78{ }^{\circ} \mathrm{C}$ for 30 minutes to give the resulting amine (11a, b) (yield: boc-piperazine: $71 \%$; imidazole: $57 \%$ ) after purification by column chromatography. The second substituent $\mathrm{R}_{2}$ (quinoxaline (1b), 3,5-difluorophenyl (2a), trifluoromethoxy phenyl (3a), biphenyl (4a) or 3-hydroxy quinoxaline (5a)) was introduced by using the respective carboxylic acids. In accordance with common peptide syntheses, the educts were dissolved in DMF followed by the addition of HATU (O- (7azabenzotriazol-1-yl) -N,N,N',N'-tetramethyl-uroniumhexa fluorophosphate) and collidine at $0^{\circ} \mathrm{C}$ and the mixture was stirred overnight at room temperature. After purification by column chromatography, the boc-piperazine was deprotected by stirring in trifluoroacetic acid to obtain the desired SIRT1 activators (1b, 2a, 3a, 4a) in good yields (53\%-81\%). All synthesized SIRT1 activators were characterized by high resolution/high accuracy mass spectrometry, ${ }_{1}^{1} \mathrm{H}$ and ${ }^{13} \mathrm{C}$ NMR spectroscopy (see supplemental information).

Conclusively, an efficient and convenient synthetic route for SIRT1 activators with an imidazo[1,2-b]thiazole-based structure was presented. The approach followed earlier protocols concerning the required intermediates but optimized conditions regarding reaction time/steps and employed educts were used. Moreover, analytical data characterizing the obtained model substances (HRMS; ${ }^{1} \mathrm{H}$ and ${ }^{13} \mathrm{C}$ NMR) of three potential SIRT1 activators (1b, 2a, 4a), the metabolite of SRT1720 (5a) and deuterated standards (6a) were provided, facilitating the production and 
characterization of structurally related compounds. The imidazo[1,2-b]thiazole-based SIRT1 activators have received considerable attention by their ability of activation in vitro, effect on metabolism in vivo animal experiments and the clinical tested SRT2104 [13, 14] which is a promising therapeutic candidate in the near future. The four model activators, metabolite and deuterated standards (1b, 2a, 3a and $\mathbf{4 a}$ ) were prepared to demonstrate the applicability of the modified synthesis for medicinal and analytical research purposes. The suggested route of synthesis allows a rapid variation of both substituents $R_{1}$ and $R_{2}$ and provided good yields for each of the six synthesis steps.

\section{CONFLICT OF INTEREST}

The authors declare no competing financial interest.

\section{ACKNOWLEDGEMENTS}

The study was conducted with support of Antidoping Switzerland (Berne, Switzerland) and the Manfred-DonikeInstitute for Doping Analysis (Cologne, Germany).

\section{SUPPLEMENTARY MATERIAL}

Synthetic procedure and compound characterization data (HRMS, ${ }^{1} \mathrm{H}$ NMR and ${ }^{13} \mathrm{C}$ NMR data).

\section{REFERENCES}

[1] Revollo, J.R.; Li, X. The ways and means that fine tune Sirt1 activity. Trends Biochem. Sci., 2013, 38(3), 160-167.

[2] Milne, J.C.; Lambert, P.D.; Schenk, S.; Carney, D.P.; Smith, J.J.; Gagne, D. J.; Jin, L.; Boss, O.; Perni, R.B.; Vu, C.B.; Bemis, J.E.; Xie, R.; Disch, J.S.; Ng, P.Y.; Nunes, J.J.; Lynch, A.V.; Yang, H.; Galonek, H.; Israelian, K.; Choy, W.; Iffland, A.; Lavu, S.; Medvedik, O.; Sinclair, D.A.; Olefsky, J.M.; Jirousek, M.R.; Elliott, P.J.; Westphal, C.H. Small molecule activators of SIRT1 as therapeutics for the treatment of type 2 diabetes. Nature, 2007, 450(7170), 712-716.

[3] Howitz, K.T.; Bitterman, K.J.; Cohen, H.Y.; Lamming, D.W.; Lavu, S.; Wood, J.G.; Zipkin, R.E.; Chung, P.; Kisielewski, A.; Zhang, L.L.; Scherer, B.; Sinclair, D.A. Small molecule activators of sirtuins extend Saccharomyces cerevisiae lifespan. Nature, 2003, 425(6954), 191-196.

[4] Hubbard, B.P.; Sinclair, D.A. Small molecule SIRT1 activators for the treatment of aging and age-related diseases. Trends Pharmacol. Sci., 2014, 35(3), 146-154.

[5] de Cabo, R.; Ellis, J.; Sinclair, D.; Minor, R.K. Sirtuin activating compounds, resveratrol and SRT1720, extend healthspan and lifespan of C57BL6 male mice. FEBS J., 2011, 278, 44.

[6] Minor, R.K.; Baur, J.A.; Gomes, A.P.; Ward, T.M.; Csiszar, A.; Mercken, E.M.; Abdelmohsen, K.; Shin, Y.K.; Canto, C.; Scheibye-Knudsen, M.; Krawczyk, M.; Irusta, P.M.; MartinMontalvo, A.; Hubbard, B.P.; Zhang, Y.; Lehrmann, E.; White, A.A.; Price, N.L.; Swindell, W.R.; Pearson, K.J.; Becker, K.G.; Bohr, V.A.; Gorospe, M.; Egan, J.M.; Talan, M.I.; Auwerx, J.; Westphal, C.H.; Ellis, J.L.; Ungvari, Z.; Vlasuk, G.P.; Elliott, P.J.; Sinclair, D.A.; de Cabo, R. SRT1720 improves survival and healthspan of obese mice. Sci. Rep., 2011, 1(70), 70.

[7] Feige, J.N.; Lagouge, M.; Canto, C.; Strehle, A.; Houten, S.M.; Milne, J.C.; Lambert, P.D.; Mataki, C.; Elliott, P.J.; Auwerx, J. Specific SIRT1 activation mimics low energy levels and protects against diet-induced metabolic disorders by enhancing fat oxidation. Cell Metab., 2008, 8(5), 347-358.

[8] Pacholec, M.; Bleasdale, J.E.; Chrunyk, B.; Cunningham, D.; Flynn, D.; Garofalo, R.S.; Griffith, D.; Griffor, M.; Loulakis, P.; Pabst, B.; Qiu, X.; Stockman, B.; Thanabal, V.; Varghese, A.; Ward, J.; Withka, J.; Ahn, K. SRT1720, SRT2183, SRT1460, and resveratrol are not direct activators of SIRT1. J. Biol. Chem., 2010, 285(11), 8340-8351.
[9] Kugel, S.; Mostoslavsky, R. SIRT1 activators: the evidence STACks up. Aging (Albany NY), 2013, 5, 142-143.

[10] Lakshminarasimhan, M.; Rauth, D.; Schutkowski, M.; Steegborn, C. Sirt1 activation by resveratrol is substrate sequence-selective. Aging (Albany NY) 2013, 5(3), 151-154.

[11] Hubbard, B.P.; Gomes, A.P.; Dai, H.; Li, J.; Case, A.W.; Considine, T.; Riera, T.V.; Lee, J.E.; E, S.Y.; Lamming, D.W.; Pentelute, B.L.; Schuman, E.R.; Stevens, L.A.; Ling, A.J.; Armour, S.M.; Michan, S.; Zhao, H.; Jiang, Y.; Sweitzer, S.M.; Blum, C.A.; Disch, J.S.; Ng, P.Y.; Howitz, K.T.; Rolo, A.P.; Hamuro, Y.; Moss, J.; Perni, R.B.; Ellis, J.L.; Vlasuk, G.P.; Sinclair, D.A. Evidence for a common mechanism of SIRT1 regulation by allosteric activators Science, 2013, 339(6124), 1216-1219.

[12] Wu, J.; Zhang, D.; Chen, L.; Li, J.; Wang, J.; Ning, C.; Yu, N.; Zhao, F.; Chen, D.; Chen, X.; Chen, K.; Jiang, H.; Liu, H.; Liu, D. Discovery and mechanism study of SIRT1 activators that promote the deacetylation of fluorophore-labeled substrate. J. Med. Chem., 2013, 56(3), 761-780.

[13] Libri, V.; Brown, A.P.; Gambarota, G.; Haddad, J.; Shields, G.S.; Dawes, H.; Pinato, D.J.; Hoffman, E.; Elliot, P.J.; Vlasuk, G.P.; Jacobson, E.; Wilkins, M.R.; Matthews, P.M. A pilot randomized, placebo controlled, double blind phase I trial of the novel SIRT1 activator SRT2104 in elderly volunteers. PLoS One, 2012, 7(12), e51395.

[14] Hoffmann, E.; Wald, J.; Lavu, S.; Roberts, J.; Beaumont, C.; Haddad, J.; Elliott, P.; Westphal, C.; Jacobson, E. Pharmacokinetics and tolerability of SRT2104, a first-in-class small molecule activator of SIRT1, after single and repeated oral administration in man. Br. J. Clin. Pharmacol., 2013, 75(1), 186196.

[15] Blum, C.A.; Ellis, J.L.; Loh, C.; Ng, P.Y.; Perni, R.B.; Stein, R.L. SIRT1 modulation as a novel approach to the treatment of diseases of aging. J. Med. Chem., 2011, 54(2), 417-432.

[16] Yoshizaki, T.; Schenk, S.; Imamura, T.; Babendure, J.L.; Sonoda, N.; Bae, E.J.; Oh, D.Y.; Lu, M.; Milne, J.C.; Westphal, C.; Bandyopadhyay, G.; Olefsky, J.M. SIRT1 inhibits inflammatory pathways in macrophages and modulates insulin sensitivity. Am. $J$. Physiol. Endocrinol. Metab., 2010, 298(3), E419-428.

[17] Höppner, S.; Schänzer, W.; Thevis, M. Mass spectrometric studies on the in vitro generated metabolites of SIRT1 activating drugs for doping control purposes. J. Mass Spectrom., 2013, 48(7), 830-843.

[18] Höppner, S.; Delahaut, P.; Schänzer, W.; Thevis, M. Mass spectrometric studies on the in vivo metabolism and excretion of SIRT1 activating drugs in rat urine, dried blood spots, and plasma samples for doping control purposes. J Pharm. Biomed. Anal., 2014, $88,649-659$

[19] Höppner, S.; Schänzer, W.; Thevis, M. Fragmentation studies of SIRT1-activating drugs and their detection in human plasma for doping control purposes. Rapid Commun. Mass Spectrom., 2013, 27(1), 35-50.

[20] Nunes, J.J.; Milne, J.; Bemis, J.; Xie, R.; Vu, C.B.; Ng, P.Y.; Disch, J.S. Sirtuin Modulating Compounds. US Patent no. 2009/0099170 A1, April 16, 2009.

[21] Vu, C.B.; Bemis, J.E.; Disch, J.S.; Ng, P.Y.; Nunes, J.J.; Milne, J.C.; Carney, D.P.; Lynch, A.V.; Smith, J.J.; Lavu, S.; Lambert, P.D.; Gagne, D.J.; Jirousek, M.R.; Schenk, S.; Olefsky, J.M.; Perni, R.B. Discovery of imidazo[1,2-b]thiazole derivatives as novel SIRT1 activators. J. Med. Chem., 2009, 52(5), 1275-1283.

[22] Sharma, S.; Saha, B.; Sawant, D.; Kundu, B. Synthesis of novel Nrich polycyclic skeletons based on azoles and pyridines. J. Comb. Chem., 2007, 9(5), 783-792.

[23] Chao, Q.; Sprankle, K.G.; Grotzfeld, R.M.; Lai, A.G.; Carter, T.A.; Velasco, A.M.; Gunawardane, R.N.; Cramer, M.D.; Gardner, M.F.; James, J.; Zarrinkar, P.P.; Patel, H.K.; Bhagwat, S.S. Identification of $\quad \mathrm{N}$-(5-tert-butyl-isoxazol-3-yl)-N'-\{4-[7-(2-morpholin-4-ylethoxy)imidazo[2,1-b][1,3]benzothiazol-2-yl]phenyl \}urea dihydrochloride (AC220), a uniquely potent, selective, and efficacious FMS-like tyrosine kinase-3 (FLT3) inhibitor. J. Med. Chem., 2009, 52(23), 7808-7816.

[24] Andreani, A.; Burnelli, S.; Granaiola, M.; Leoni, A.; Locatelli, A.; Morigi, R.; Rambaldi, M.; Varoli, L.; Calonghi, N.; Cappadone, C.; Farruggia, G.; Zini, M.; Stefanelli, C.; Masotti, L.; Radin, N.S.; Shoemaker, R.H. New antitumor imidazo[2,1-b]thiazole guanylhydrazones and analogues. J. Med. Chem., 2008, 51(23), 809-816. 
[25] Andreani, A.; Granaiola, M.; Leoni, A.; Locatelli, A.; Morigi, R.; Rambaldi, M.; Lenaz, G.; Fato, R.; Bergamini, C.; Farruggia, G. Potential antitumor agents. 37. Synthesis and antitumor activity of guanylhydrazones from imidazo[2,1-b]thiazoles and from the new heterocyclic system thiazolo[2',3':2,3]imidazo[4,5-c]quinoline. $J$. Med. Chem., 2005, 48(8), 3085-3089.

(C) Höppner et al.; Licensee Bentham Open.

This is an open access article licensed under the terms of the Creative Commons Attribution Non-Commercial License (http://creativecommons.org/licenses/ by-nc/3.0/) which permits unrestricted, non-commercial use, distribution and reproduction in any medium, provided the work is properly cited. 